\title{
ESTRATÉGIA DE NEGÓCIOS: PLANEJAMENTO A LONGO PRAZO
}

\section{JOÃO BOSCO LODI}

Sumário: 1. Conceito de estratégia. 2. Estratégias típicas. 3. Flexibilidade, um objetivo estratégico. 4. As sessóes de formulação estratégica. 5. Comportamento estratégico versus resultados a curto prazo. 6. Conclusão.

Suponha que a sua emprêsa já tenha chegado ao ponto de dominar a complexa técnica de comunicar e controlar os objetivos a curto prazo. A êste respeito, nessa mesma revista ( $R A E$ n. ${ }^{\circ} 24$, setembro de 1967) escrevi um artigo que procurava analisar a mecânica dos Objetivos de Gerência em base anual: A Técnica de Fixação de Objetivos para Gerentes. Agora, a próxima preocupação de uma emprêsa, que está segura de obter bons resultados com os objetivos a curto prazo, consiste em que essas metas se apoiem numa estimativa do que espera alcançar a longo prazo. A transição do enfoque a curto prazo, que pode ser míope e conduzir à beira de abismo, para o enfoque a longo e curto prazo é um progresso da administração. A emprêsa que já assegurou o seu manejo do presente está agora avançando para o próximo futuro. $O$ objetivo dêste artigo é superar o anterior naquilo que lhe faltou de visão a longo prazo.

Nas diversas vêzes em que êste trabalho foi reescrito durante o ano de 1968, a posição dos amigos que o debaJoÃo BosCo LODI - Consultor para desenvolvimento de executivos num grupo de emprêsas brasileiras. E licenciado em Filosofia pela Universidade Gregoriana de Roma, e pela Universidade de São Paulo. Autor dos livros Manual de Entrevistas de Pessoal, Recrutamento de Pessoal e Desenvolvimento de Executivos no Brasil, editados pela Livraria Pioneira Editôra.

R. Adm. Emp., Rio de Janeiro, 9 (1): p. 5-32, jan.-mar. 1969 
teram variou num aspecto considerável. $\mathrm{O}$ editor de uma revista econômica achou o tema teórico e desinteressante para o empresariado brasileiro "que está apenas interessado em temas práticos", isto é, que se alimenta da culinária administrativa mensal receitada por êle e por alguns outros editôres. Outro amigo sugeriu dar um tratamento quantitativo à questão, empregando a teoria de jogos, que não é o adotado aqui, por prender-se o autor mais aos aspectos conceptuais e ao clima gerencial da emprêsa. Outros, enfim, identificaram-se com as idéias dêste artigo porque suas emprêsas já estão vivendo a realidade do planejamento global a longo prazo. Êle pode interessar ainda aos estudantes de Diretrizes Administrativas, dos cursos de Administração de Emprêsas.

Ao começar a sua elaboração, o autor se propôs diversas perguntas que o leitor também deve estar fazendo no momento em que inicia a leitura. O que é estratégia? Como distingui-la da tática? Como aplicar a teoria estratégica aos negócios? Quais são os principais tipos de estratégia empregados pelas emprêsas? Será necessária estratégia? Qual é a alternativa para o seu emprêgo? Como se ligam estratégia e planejamento a longo prazo? Como formular uma estratégia de negócios? Como ligar os objetivos a longo prazo com a avaliação do desempenho dos gerentes, com o sistema de remuneração e com os critérios de promoção?

\section{CONCEITO DE ESTRATÉgIA}

A estratégia é a aplicação de fôrças em larga escala contra um inimigo. Este antigo conceito militar pode ser transposto ao meio empresarial na seguinte forma: estratégia é a mobilização de todos os recursos da emprêsa no âmbito nacional ou internacional visando a atingir objetivos a longo prazo. Tática é um esquema específico de emprêgo de recursos dentro de uma estratégia geral. No plano militar, uma mobilização de tropa é uma tática dentro de uma estratégia mais ampla; no plano gerencial, o orçamento anual, ou o plano anual de inversóes, é um plano 
tático dentro de uma estratégia global a longo prazo. Uma guerra requer uma ou mais estratégias; cada estratégia leva à proliferação de ações ou medidas táticas. $O$ planejamento para cinco anos na emprêsa requer uma estratégia, à qual se ligam os planos táticos de cada ano compreendido nesse período.

Muitos empresários são mais táticos do que estrategistas porque são mais felizes numa determinada ação concreta e menos no conjunto de ações que se integram numa estratégia. Falar em estratégia nos estágios anteriores de desenvolvimento empresarial era produzir pouco interêsse. O entrepreneur primitivo, o pioneiro industrial, agindo numa base intuitiva e sempre desconfiado de planejamento, foi mais avêsso à estratégia, preferindo as táticas inspiradas no momento. Durante os anos em que se implantou a indústria brasileira e em que nosso sistema industrial foi sendo integrado no sistema internacional, a estratégia foi subindo de importância. $\mathrm{O}$ mundo foi ficando pequeno; os sub-sistemas nacionais, cada vez menos isolados do sistema internacional; a competição foi aumentando e a prevenção contra crises custosas foi levando a emprêsa à elaboração de estratégias defensivas e ofensivas.

De início, há alguns malentendidos por esclarecer. Em primeiro lugar, quando se constrói uma estratégia não se pretende tomar hoje decisões sôbre o futuro, mas tomar hoje decisões tendo em mente o futuro. Veja-se o que DRUCKER diz: “. . . o planejamento não representa o domínio mental do futuro ... Qualquer tentativa nesse sentido é insensatez. As criaturas humanas não podem prever nem controlar o futuro. A pretensão de assenhorear-se do futuro é infantilidade e nossos esforços nesse sentido só podem desacreditar o nosso trabalho. Pode-se partir logo da conclusão de que a previsão, além dos prazos mais curtos, não merece respeito nem vale a pena. $O$ planejamento a longo prazo é necessário justamente em virtude da nossa incapacidade de prever. Existe, porém, outra razão mais poderosa que faz constatar qual será o mais provável curso dos acontecimentos ou, no máximo, apurar 
uma série de probabilidades. Todavia, o problema empresarial é o único capaz de modificar as possibilidades, uma vez que o universo da emprêsa não é composto de matéria, mas de valor. Com efeito, a principal contribuição da emprêsa, aliás a única que tem como recompensa o lucro, é fazer com que haja uma ocorrência exclusiva, a inovação que altera as probabilidades"'.

Em segundo lugar, a estratégia não deve ser confundida com um de seus planos táticos; estratégia não é só inovação, ou só diversificação ou planejamento financeiro, mas o conjunto disso dirigido a objetivos a longo prazo que se pretendem atingir. Em terceiro lugar, a estratégia não é um fim em si mesma, porém, apenas um meio. Um plano a longo prazo pode ficar obsoleto na semana seguinte; o processo mental que criou êsse plano e o reavalia em cada ocasião significativa é que não se obsoletiza. Em quarto lugar, a estratégia não dá certeza, mas apenas probabilidade. Quem busca certeza não pode pensar no amanhã. Só ontem e hoje são certos. Queixava-se um gerente: "Êles não entendem a natureza da estimativa, êles querem respostas". KenNETH E. Boulding, professor de Economia da Universidade de Michigan, em resposta a uma pesquisa de STEWART THOMPSON para a AMA, diz: "Um dos aspectos do planejamento de uma firma que eu considero interessante é a sua relação com todo o futuro da sociedade a longo prazo, a que chamo de a dinâmica da sociedade a longo prazo. Em primeiro lugar, temos as projeções simples, ou seja, se a pessoa está indo para os andares superiores, vai continuar subindo. As projeções lineares são convenientes para indicar o que poderá acontecer se o que é feito agora continuar a ser processado da mesma forma, como por exemplo, se o ritmo das alterações se mantiver. Penso que a dificuldade das predições em ciências sociais está no fato de encontrarmos sistemas que estão sujeitos a acentuadas inconstâncias, ao contrário dos

1 Drucker, Peter F. Planejamento a Longo Prazo: Desafio à Ciência da Administração, Journal of the Institute of Management Sciences, abril de 1959. 
sistemas astronômicos que nos permitem predizer com segurança diferenciais muito simples que esperamos se mantenham inalteradas" 2 .

Cabe ainda, preliminarmente, perguntar se a estratégia é necessária e qual seria a sua alternativa. A alternativa consiste em avaliar cada oportunidade, quando surge, à luz do momento, em vista da lucratividade individual daquela oportunidade. Essa forma de oportunismo, que é muito própria ao comerciante primitivo, tem suas vantagens: a) a firma economiza tempo, dinheiro e talento executivo que seriam gastos na formulação estratégica; b) as oportunidades aparecem de qualquer modo, com ou sem estratégia; c) e, finalmente, a firma retarda seu comprometimento até o momento em que a oportunidade estiver na mão.

Por outro lado, o oportunismo como filosofia de negócios, tem grandes desvantagens: a) na ausência de estratégia, não há regras para procurar novas oportunidades; b) as decisões que envolvam projetos preparatórios serão pobres; c) não haverá outra forma senão a lucratividade individual para medir o valor de uma dada ação; d) a firma não está preparada para se antecipar às mudanças. Em geral, a não-estratégia está caracterizada num tipo de emprêsa e de empresário. A pequena e vulnerável emprêsa, próxima à bancarrota, especulando o momento presente, não tem planos a longo prazo nem se pode dar ao luxo de diluir recursos em projetos para o futuro. Há um tipo de empresário, altamente intuitivo e personalista, que trabalha na base da agenda diária, respondendo às pressões do momento.

2. ESTRATÉGIAS TÍPICAS E HIERARQUIA DE OBJETIVOS

H. IGOR ANSOFF ${ }^{3}$ expõe diversas categrias estratégicas. Segundo êle, cada emprêsa se enquadra em uma dessas categorias quando o seu comportamento é coerentemente dirigido a determinados objetivos.

2 Thompson, Stewart. How Companies Plan, American Management Association, Nova Iorque, 1962. Tradução brasileira: Como as Emprêsas Planejam, São Paulo, Management Center do Brasil, 1967.

3 Ansoff, H. Igor. Corporate Strategy, Nova Iorque, McGraw-Hill, 1965. 
2.1. Máximo rendimento atual. A estratégia dêsse tipo de administração consiste em tirar fora da firma o mais possível de seu ativo e para isso procura-se maximizar a liquidez de caixa. Êsse tipo de emprêsa se assemelha à galinha dos ovos de ouro; ela não é extinguida, apenas para poder continuar produzindo rendimentos.

2.2. Ganhos de capital. A estratégia dêsse tipo de administração visa a criar uma imagem pública de firma que cresce rápido. As decisões tomadas visam a obter lucratividade a curto prazo, com exclusão dos objetivos a longo prazo e dos objetivos de flexibilidade, que se explicará mais adiante. Mesmo ameaçada de perecer na primeira crise, êsse tipo de firma ou pretende atrair capital ou pretende atrair atenção sôbre si, a curto prazo, numa ação relâmpago.

2.3. Liquidez de patrimônio. A estratégia desta firma consiste, bàsicamente, em atrair compradores, seja porque se pretende vender a firma, fundi-la com outra ou abrir seu capital. A ação gerencial é dirigida a demonstrar um alto grau de flexibilidade patrimonial, mesmo a custo da rentabilidade.

2.4. Responsabilidade social: interêsse iluminado. Êste tipo de estratégia consiste em mostrar preocupações cívicas e nacionais, com as quais o seu nome se acha identificado. O exemplo comum é o das emprêsas de fabricação de papel que se empenham em campanhas pela proteção das reservas florestais.

2.5. Filantropia. Esta estratégia se assemelha à anterior, à medida que a emprêsa dedica recursos para apoiar objetivos não econômicos e instituições não lucrativas, como as fundações científicas ou humanitárias. A diferença entre esta e a estratégia anterior consiste em que os ganhos dêste tipo de emprêsa são sifonados para fora. $\mathrm{Na}$ categoria anterior, os recursos aplicados em campanhas cívicas revertem-se a longo prazo, à medida que essas campanhas defendem os interêsses de mercado da emprêsa. 
2.6. Atitude para com os riscos. Uma gerência velha que pretende se perpetuar no poder tende a reduzir os riscos do negócio, mesmo que isso também reduza o volume de ganhos. Uma gerência jovem e ambiciosa adota uma estratégia de riscos diferentes, visando a um aumento de poder econômico.

Os seis tipos de estratégia apresentados por ANsoff não representam, certamente, tôda a tipologia possivel. Além da possibilidade de outras modalidades não descritas aqui, ocorrem os tipos combinados, em que duas das categorias acima podem fundir-se. É mais raro encontrar-se o tipo puro de emprêsa, de uma só orientação estratégica, do que o tipo combinado, ou às vêzes pendular, entre duas combinações.

Para que uma emprêsa chegue a um dos comportamentos descritos acima é preciso que os seus diversos objetivos se organizem de uma determinada forma. E o que se costuma chamar de hierarquia de objetivas. Para se identificar ou formular a estratégia de uma emprêsa é preciso ter uma idéia da lista geral de seus objetivos. Esta lista geral é o resultado de três fatôres principais: as influências econômicas do meio em que a firma se situa, as influências não econômicas (sociais, políticas, culturais) dêsse meio e as influências geradas dentro da emprêsa. Êste último grupo de fatôres estratégicos pode também ser subdividido em três grupos de influência: os objetivos econômicos da emprêsa, os objetivos não econômicos e as responsabilidades e restrições em que a firma se enquadra.

Apenas para detalhar ainda mais, e para demonstrar a complexidade da hierarquia dos objetivos, seguem-se os fatôres de que dependem os objetivos não econômicos da emprêsa. $O$ quadro dos objetivos não econômicos da firma é composto, antes de tudo, dos objetivos econômicos dos funcionários da emprêsa: sua preocupação pela renda atual, sua estratégia de ganhos capitais, sua necessidade de renda líquida, de segurança e de benefícios. A pressão econômica dos indivíduos sôbre a emprêsa leva-a a definir 
objetivos sociais internos, que não são puramente econômicos. A êsses, acrescentam-se os objetivos não econômicos dos indivíduos: sua necessidade de auto-realização, de status e reputação, de ética e de filantropia, os quais geram necessidades não econômicas dentro da firma.

Uma imagem visual mostraria que a hierarquia de objetivos da emprêsa se estrutura em forma de pirâmide, em cuja base estão os objetivos econômicos e não econômicos de seus empregados e em cujo tôpo estaria a estratégia adotada pela emprêsa. Sendo esta última um produto de tão complexa equação, torna-se difícil explicar porque a emprêsa se comporta de determinada maneira. $O$ interêsse do estudo dêsses fatôres complexos que se somam, subtraem $\mathbf{e}$ multiplicam, consiste em descobrir o mecanismo pelo qual se formula uma estratégia global de emprêsa. Para maior penetração neste tema, o leitor interessado encontra no já citado livro de ANSOFF um gráfico interessante ${ }^{4}$ que ilustra êsse conceito da hierarquização dos objetivos. Aliás, a propósito, essa obra de ANSOFf apresenta uma série considerável de modelos teóricos relacionados com os temas tratados nestes três últimos parágrafos; êsses modelos não só são esclarecedores, como dão o exemplo para o florescente ramo da administração atual, que se poderia chamar de modelística.

\section{FLEXIBILIDADE, UM OBJETIVO ESTRATÉGICO}

Uma estratégia, quando não está em função de uma liquidação da firma a curto prazo, visa a um conjunto de metas a longo prazo em que se misturam objetivos econômicos e não econômicos. Os objetivos de lucro a longo prazo são, em geral, os que arrastam os demais. Quase tôda emprêsa se propóe êsse tipo de objetivos, mas poucas visam a um alvo mais elevado do que aquêle que permita ver o prognóstico atual. Os outros objetivos, em parte, preenchem a lacuna entre o prognóstico atual e a meta a longo prazo. Vamos esclarecer. Qualquer pessoa é capaz de ver para onde vai o negócio nos próximos cinco anos, se fizer uma

4dem, ibidem, p. 69. 
projeção dos lucros com correção monetária. Chame-se esta projeção de prognóstico atual. Esta estimativa não tem em vista nem uma previsão dos esforços que a emprêsa pode empreender, nem uma análise do obsoletismo crescente de seus produtos, maquinismos e pessoas, mas, meramente, uma suposição de que a emprêsa continue a ganhar como ganha hoje. Acima dessa linha prognóstico atual, risca-se outra, ascendente, nos próximos cinco anos, a de meta de lucro a longo prazo. Esta tem que ter em vista o esfôrço que a emprêsa deverá despender para chegar a um ponto ideal. A brecha formada entre a linha de prognóstico atual e a linha de meta a longo prazo deve ser preenchida com objetivos financeiros e de produtomercado. Para preencher essa brecha de lucros, que também é uma brecha de vendas, a emprêsa deve desenvolver uma estratégia de produto-mercado. Nesta estratégia há quatro combinações: a) produto atual no mercado atual: maior penetração no mercado; b) produto atual em mercado nôvo: desenvolvimento de mercados; c) produto nôvo no mercado atual: desenvolvimento de produtos para o mesmo consumidor; d) produto nôvo em mercado nôvo: a diversificação pura. As combinações $a, b, c$ representam uma estratégia de expansão. Ũnicamente a combinação $d$ é a estratégia de diversificação.

A diversificação de produtos assim como a liquidez de recursos internos (turnover do patrimônio líquido, capital de giro, giro de estoque, dívida da clientela, idade do ativo fixo) representam objetivos de flexibilidade do negócio. A flexibilidade da emprêsa pode ser distinguida em duas categorias: defensiva e ofensiva. A flexibilidade defensiva é representada pelo número de clientes independentes, que detêm uma porção substancial de vendas, pelo número de segmentos do mercado da firma, que pertencem a economias diferentes, e pelo número de tecnologias diferentes em que a firma se apoia. A flexibilidade ofensiva é representada pela participação em áreas novas de pesquisa e pela fôrça relativa da emprêsa nestas áreas. 
Essa distinção provém de um antigo e ainda válido conceito militar de que o exército precisa ter flexibilidade para responder a ataques inimigos em contingências imprevisíveis. Assim é que se costuma distinguir a flexibilidade externa e a interna. A flexibilidade militar externa se compõe de objetivos ofensivos e defensivos. Ofensivos são os objetivos que se traduzem em número de iniciativas sôbre o inimigo e fôrça destas iniciativas. Defensivos são os objetivos que visam a evitar que a sorte da guerra dependa da defesa de umas poucas praças, de poucas frentes de batalha ou de poucas unidades. A flexibilidade interna significa liquidez, rapidez de conversão dos recursos, para responder a essas contingências imprevisíveis.

Voltando ao âmbito da emprêsa, definiu-se como objetivo de flexibilidade o seu retôrno sôbre investimentos em contingências imprevisíveis. Êste retôrno de capital depende de uma flexibilidade externa, que é o impacto da emprêsa sôbre as contingências e uma flexibilidade interna, que é a capacidade da emprêsa de responder ao imprevisível. A flexibilidade externa da emprêsa pode ser ofensiva e defensiva. A flexibilidade ofensiva é representada pelo número de tecnologias férteis de que a emprêsa participa e pela fôrça de sua pesquisa. A flexibilidade defensiva é representada pelo número de clientes independentes, que detêm uma porção substancial de vendas, pelo número de segmentos do mercado da firma, que pertencem a economias diferentes, e pelo número de tecnologias diferentes em que a firma se apoia. A flexibilidade interna da emprêsa é representada pelos objetivos de liquidez: índice de liquidez, proporção entre dívidas e cobranças, idade das fábricas e maquinismos, obsoletismo e antiguidade dos gerentes, giro dos estoques, imobilizado. A flexibilidade externa pode também ser chamada de "capacidade competitiva". No aspecto ofensivo, a emprêsa deve procurar expandir-se e diversificar-se. Sua flexibilidade ofensiva é medida por alguns índices conhecidos: a) índice de crescimento em vendas; b) índice de crescimento em lucros; c) índice de crescimento da participação no mercado; d) 
expansão na linha de produtos; e) expansão no âmbito do mercado.

No aspecto defensivo, a emprêsa fixa objetivos de estabilidade: redução da flutuação nas vendas, redução de flutuação nos lucros, utilização de sua capacidade. Para que uma emprêsa possa sentir-se mais livre e independente das contingências dos produtos e mercados atuais é preciso fixar objetivos de diversificação. Pode-se então perguntar: quando as emprêsas devem pensar em diversificação? 1. Quando seus objetivos já não podem ser atingidos pela expansão. Quando ocorre uma saturação de mercado, declínio da demanda, pressões da competição, obsolescência da linha de produtos. 2. Quando o dinheiro retido excede às necessidades totais de expansão e os acionistas fazem pressão sôbre a firma para investir com mais lucro. 3. Quando as oportunidades de diversificação prometem maior rentabilidade do que as oportunidades de expansão. 4. Quando as informações não permitem uma comparação segura entre expansão e diversificação.

4. AS SESSÕES DE FORMULAÇÃo ESTRATÉGICA

O esquema proposto para a formulação de uma estratégia é que a Direção e a Alta Gerência se reúnam num mínimo de seis sessões de discussão em grupo, com a duração total de aproximadamente vinte horas. Cada uma dessas sessões, de três horas de duração, será dedicada à discussão de um dos temas centrais: objetivos, estratégia financeira, estratégia de recursos e capacidades, produto-mercado, inovação tecnológica, adaptação de estrutura e da gerência aos objetivos estratégicos. Essas reuniões devem desenvolverse em local afastado de interferências da rotina da emprêsa, de modo que cada participante possa dar o melhor de si. Recomenda-se a utilização do seminário residencial, de três dias consecutivos, em instalação que convide à reflexão, fora do ruído das grandes cidades. Cada sessão poderá ser regida pelos questionários que ofereço em seguida. Os participantes devem receber êsses questionários pelo menos uma semana antes de partir para o seminário. 
A formulação estratégica se inicia com a enunciação das suposições básicas dos dirigentes. A estas segue-se a avaliação da capacidade interna da emprêsa, a avaliação das oportunidades externas e a avaliação das expectativas dos acionistas, que ainda constituem, em muitas firmas, uma condição essencial de desenvolvimento. $\mathrm{Na}$ expectativa dos acionistas pode ser incluída aquela parcela de expectativas e suposições básicas da alta gerência da emprêsa, que, reciprocamente, recebe e exerce influência sôbre os acionistas. Nesse ponto, toma-se alguma decisão sôbre diversificação. Uma vez definido o plano estratégico, dá-se a última demão aos planos táticos, alguns dos quais já estão em rascunho. Pretender saber o que deve vir antes, plano estratégico ou planos táticos, é o mesmo que pretender saber se a galinha existiu antes do ôvo. Na realidadade os dois tipos de planos estão sendo feitos em paralelo e recebendo influências recíprocas. Quando o plano estratégico está terminado, faz-se uma última revisão nos planos táticos de modo a acertar suas linhas de orientação com as grandes linhas do negócio expostas no plano estratégico. Exemplos de planos táticos anuais podem-se citar: o Plano de Marketing, o Plano de Produção, o Plano de Materiais, o Plano de Inversões, o Plano de Recursos Humanos, o Plano de Recursos Financeiros, o Plano de Pesquisa, o Plano de Fusões e Aquisições, o Plano de Diversificação, o Plano de Integração, o Plano de Liquidação.

Anualmente, a direção da emprêsa deve reunir-se para rever o plano estratégico e orientar as revisóes dos planos táticos. Feito isto, êsse conjunto de planos deve ser comunicado aos diversos níveis executivos, ocasião em que são feitos os planos de ação individuais, de modo que cada executivo saiba onde dar a sua melhor contribuição. Êsse conjunto de trabalhos, também chamado de Administração por Objetivos, inspirado originalmente na obra de Peter F. DRUCker, deve ser realizado no início de cada exercício fiscal da emprêsa, para que todo o esfôrço seja combinado com o da vida da emprêsa. $O$ desenvolvimento gerencial deve ser estimulado a girar em tôrno da estra- 
tégia da emprêsa. No artigo anterior ( $R A E$ n. $\left.{ }^{\circ} 24\right)$ mostrou-se a ligação dos objetivos anuais da Companhia com o desenvolvimento dos executivos. Depois daquele trabalho, foi-se amadurecendo a idéia da ligação entre os objetivos a longo prazo e êsse mesmo desenvolvimento de executivos. A Figura 1 ilustra melhor o que penso.

\section{Figura 1 - Desenvolvimento de Executivos e Estratégia de Negócios}

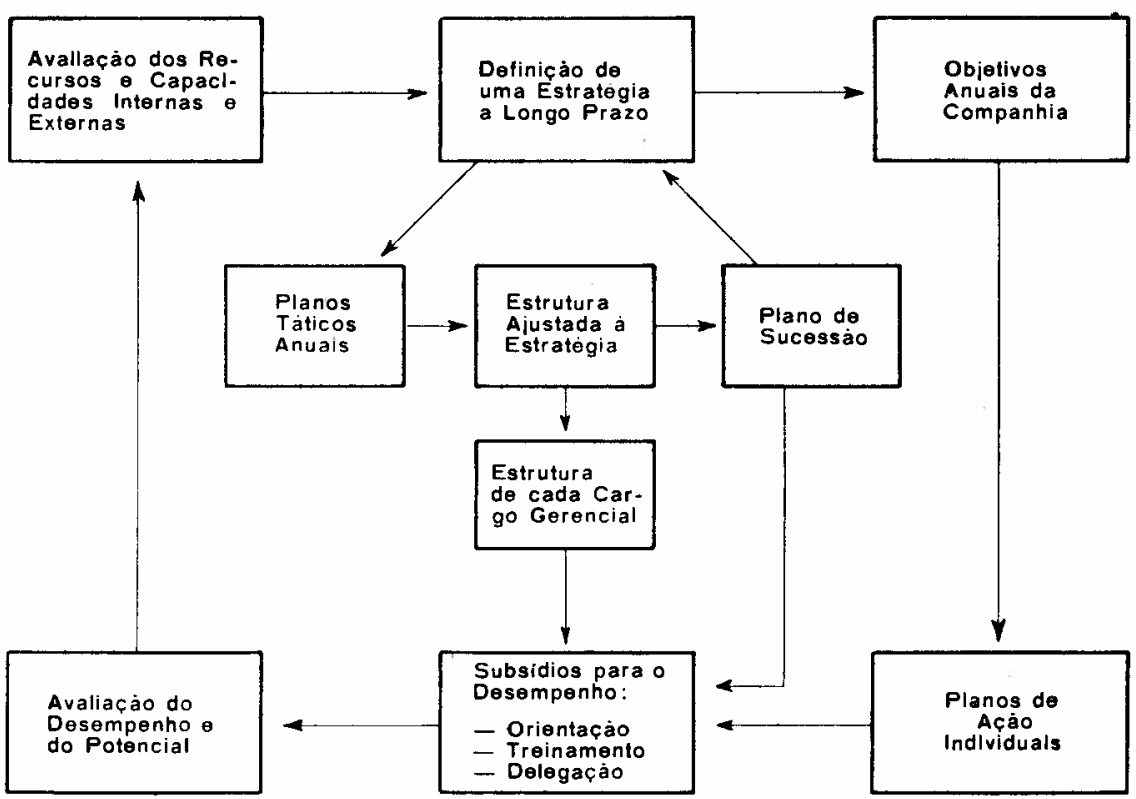

PRIMEIRA SESSÃO: OBJETIVOS GERAIS DA EMPRÊSA

1 Quais são as nossas suposições básicas para os próximos cinco anos, em vista das influências do exterior, da nação, da comunidade, da família, em relação à política, economia, sociedade, população, renda, hábitos e costumes, tecnologia, inovações, etc.?

2 Existem falhas importantes em nosso conhecimento dêsses fatôres externos à emprêsa, que deveriam ser preenchidas com informação? 
3 Do ponto de vista das influências externas, quais são as oportunidades e ameaças mais evidentes que, provàvelmente, aparecerão em curto/longo prazo?

4 Em que negócio estamos, realmente?

5 Qual é a nossa capacidade mais característica?

6 Que problemas, em nossos negócios, são tão críticos, hoje em dia, que o fracasso em resolvê-los pode comprometer nosso futuro? Que planos temos para resolvê-lcs?

7 Quais são as oportunidades significativas que deveriam ser aproveitadas muito mais vigorosamente? Que planos temos para aproveitá-las?

8 Que tipo de negócios - em tamanho, mercado, produtos, recursos materiais, etc. - acreditamos ter dentro de cinco anos?

9 Temos planejado realmente para obter todos os ganhos possíveis do nosso atual negócio?

10 Existe uma falha nos lucros que deve ser coberta por fusão, aquisição ou novos produtos?

11 Podemos identificar o segrêdo do nosso êxito passado?

12 Como conseguimos chegar ao ponto em que estamos?

a) Qual foi anteriormente e é agora a nossa posição no mercado?

b) Que importância tiveram em nosso crescimento as melhorias tecnológicas anteriores?

c) O nosso sucesso anterior foi obra de alguns homens-chave?

d) A política financeira que temos adotado continua nos sendo útil?

13 Que podemos fazer sem alteração de nossas diretrizes?

a) Quais serão nossos mercados?

b) Qual é a nossa fôrça competitiva?

- futura base de preços?

- reputaçãa?

c) Disporemos de recursos suficientes (pessoal, dinheiro e fábricas)?

d) Nosso atual volume de pesquisas e desenvolvimento produz uma quantidade suficiente de novos produtos?

e) Que volumes de vendas e lucratividade poderão ser conseguidos pelos diversos centros de lucros, em proporção aos recursos apropriados para cada um?

14 Será isso mesmo o que queremos alcançar?

a) Que critério podemos adotar para medir a satisfação?

- Que teoria sôbre atividades comerciais queremos defender? 
- Com base na mesma, que objetivos poderemos estabelecer?

- Que metas específicas necessitamos alcançar?

b) Qual é a situação atual da emprêsa e a sua projeção futura em face dos referidos critérios?

15 Como podemos modificar as nossas atividades atuais?

a) Que novos produtos devem ser procurados?

b) Podemos atingir novos mercados com os nossos atuais produtos?

c) A modificação da nossa estratégia de mercado nos trará benefícios?

d) Deve-se estudar importante ampliaçãc ou redução das nossas instalações fabris?

e) Que novos funcionários são necessários?

f) Será conveniente alterar a organização?

g) Como poderemos fortalecer nossa situação financeira para atender necessidades futuras?

h) Devemos crescer de dentro para fora (isto é, com base em pesquisas e desenvolvimento) ou de fora para dentro (mediante aquisições de firmas e licenças para fabricar)?

16 Com tal alteração, aproximar-nos-emos dos nossos objetivos?

a) Qual será o resultado final de tôdas as alteraçóes?

b) Que grau de prioridade se deve dar a cada uma delas?

- Que prazos estipular num programa de modificações?

c) Quem será o responsável pela execução da cada programa?

17 Estamos colocando erradamente recursos de alta qualidade em oportunidades de pouco valor?

18 Existem atividades que não se ajustam ao esquema planejado da emprêsa ou atividades não rendosas que devam ser eliminadas?

\section{SEGUNDA SESSÃO: ESTRATÉGIA FINANCEIRA}

1 Como se comparam nossos coeficientes-chaves com a média da indústria e com nossos competidores principais?

2 Mesmo que a comparação seja favorável, estamos satisfeitos com êles?

3 Os lucros sôbre o ativo criam a possibilidade de atrair a quantidade de capital necessário quando o precisamos, a um preço razoável? 
4 Esólida a estrutura de nosso capital?

5 Estisfatório o fluxo do efetivo para o próximo ano? Para os próximos cinco anos?

6 Quais são os desejos e as esperanças dos acionistas do nosso negócio? Que deveremos fazer durante os próximos cinco anos para satisfazer nossos acionistas?

7 Que grau de risco estão dispostos a assumir?

8 Quais os objetivos que deveriam ser estabelecidos para os próximos cinco anos?

9 Qual deveria ser nossa filosofia básica de administração financeira?

10 Quais os programas de que necessitamos nesse período para recrutar, selecionar, treinar, supervisionar, compensar, estimular e avaliar o pessoal da área financeira?

11 Que espécie de desenvolvimento de executivos será necessário?

12 Quais as eficiências e deficiências de nossa supervisão financeira?

13 Como pode a gerência financeira contribuir para o estabelecimento de objetivos para novos desenvolvimentos de negócios, pesquisa e desenvolvimento, produção, marketing, e para objetivos jurídicos e trabalhistas?

14 Quais deveriam ser os objetivos da gerência financeira com relação à integração de sua função com tôdas as funções acima?

\section{TERCEIRA SESSÃO: ESTRATÉGIA PRODUTO-MERCADO}

1 O mercado, em geral, está crescendo ou diminuindo e qual é a tendência de nossa participação no mesmo? Qual é a nossa posição atual e dos últimos cinco anos?

2 Podemcs ligar essa tendência com outra do meio ambiente, por exemplo: crescimento da população, aumento da produção nacional, etc.?

3 Quem é realmente o consumidor? Por exemplo: sabemos quem dá a decisão final para comprar?

4 Sabemos por que o cliente compra os produtos de nós e não de nossos competidores? Por exemplo: que satisfação, serviço, fins específicos, proporciona nosso produto?

5 Dependemos em alto grau de uns poucos clientes?

6 Onde é adquirido nosso produto? Utilizamos os canais corretos de distribuição? Quais são nossos principais competidores? Podemos estimar suas fôrças e debilidades, comparando-as com as nossas? 
7 Existe ameaça de alguma nova concorrência, diretamente ou indiretamente, proporcionando outros meios para satisfazer às necessidades básicas de nossos clientes?

8 Existem restrições que não podemos alterar?

9 Existem substitutos competitivos para os principais produtos da emprêsa?

10. Tem nossa linha de produtos uma estrutura lógica?

11 São nossos produtos vulneráveis com relação às alterações tecnológicas e à obsolescência?

12 E nossa estrutura de preços competitiva e lógica?

13 Quais são os principais fatôres conhecidos que podem incidir na política de fixação de preços?

14 Existem oportunidades para desenvolver:

- produtos atuais em mercadcs atuais?

- novos produtos em mercados atuais?

- produtos atuais em novos mercados?

- novos produtos em novos mercados?

15 Quais os principais consumidores nos mercados importantes para a companhia?

16 Quais as atitudes favoráveis ou desfavoráveis dêsses consumidores em relação aos produtos da companhia?

17 Quais as mudanças ou tendências nos hábitos de compra que são evidentes nesses grupos consumidores?

18 Quais os mercados que deveriam ser servidos? Exemplo: con. sumidores institucionais, governamentais?

19 Quais as divisões específicas dêsses mercados que deveriam ser envidadas?

20 Qual a percentagem de nossas vendas totais que deveria ser representada em cada uma dessas divisóes de mercado?

21 Quais o tamanho potencial e tendência de expansão em cada uma dessas divisões?

22 Qual é a duração provável de cada uma dessas divisões, considerando-se os produtos da emprêsa?

23 Quais são as principais vantagens ou desvantagens dêsses mercados que afetarão o futuro da emprêsa?

24 Quais são as necessidades básicas dos consumidores que a emprêsa está tentando servir nesses mercados?

25 Qual deveria ser nosso produto básico?

26 Quais as principais eficiências e deficiências em nossa linha de produtos atual? 
27 Quais os produtos ou linhas de produtos que serão eliminados nesse período?

28 Quais os produtos ou linhas de produtos que serão modificados e qual é o objetivo geral durante êsse período?

29 Quais os novos produtos que terão que ser desenvolvidos e anexados às nossas linhas de produtos durante êsse período?

30 Quais as novas tecnologias ou equipamentos e instalações necessários para realizar o projeto?

31 Qual será a natureza de nossa competição direta nesse período?

32 Qual será nossa filosofia básica de competição?

33 Quais seriam os objetivos básicos com relação à posição da indústria, mercado, linha de produto em competição, etc.?

34 Quais seriam nossos objetivos com fins lucrativos nesse período?

35 Que podemos antecipar com relação às tendências de custo no mercado durante êsse período?

36 Qual deveria ser nossa norma básica de preços (política de preços)?

37 Quais deveriam ser nossos objetivos básicos com relação à estabilidade financeira, desenvolvimento de capital, risco?

38 Quais deveriam ser os objetivos básicos do nosso planejamento de mercados?

39 Quais as eficiências e deficiências de nossas operações atuais com relação a êsses objetivos?

40 Quais o tipo e o tamanho de organização necessários para alcançar êsses objetivos?

41 Qual a imagem da emprêsa que tentaremos criar junto aos consumidores, acionistas, empregados e outros na esfera social e de negócios?

42 Que podemos antecipar com relação às futuras relações com agências de propaganda?

43 Quais são nossas eficiências e deficiências nas operações de venda e distribuição?

44 Quais seriam nossos objetivos quanto ao volume de vendas para tôda a companhia?

45 Quais as modificações ou desenvolvimentos de nossos programas de recrutamento e treinamento necessários?

46 Qual seria nossa estratégia básica para o desenvolvimento do revendedor?

47 Qual o programa de desenvolvimento de executivos necessário?

48 Com que deveria e poderia a gerência de marketing contribuir para o estabelecimento de objetivos para o desenvolvimento 
de nossos negócios, pesquisa e desenvolvimento, produção, finanças, gerência da emprêsa e para objetivos jurídicos e trabalhistas?

49 Quais deveriam ser os objetivos da gerência de marketing com relação à sua integração com tôdas as funções acima?

50 Quais são nossas deficiências atuais em relação ao acima mencionado?

\section{QUARTA SESSÃO: ESTRATÉGIA DE RECURSOS E CAPACIDADE}

1 Há uma falta de plantas ou equipamentos que impede a realização de vendas lucrativas?

2 De que maneira se comparam com os padrões anteriores as medidas de eficiência como: utilização de maquinaria, utilização do trabalho, custo de manutenção por unidades de produto?

3 Usamos plenamente técnicas tais como estudo do trabalho, análises de valôres, análise de caminho crítico, etc., para incrementar nossa eficiência?

4 Estamos satisfeitos com o desenho do produto quanto à facilidade para sua fabricação?

5 Teríamos especificações de qualidade satisfatórias?

6 Estamos tratando de introduzir excessiva qualidade em nossas plantas e produtos ou não apenas a suficiente?

7 Que grau de exatidão têm nossas estimativas e planificação?

8 Há oportunidades para padronizar nossos produtos?

9 E satisfatório o rendimento de nossos materiais?

10 É satisfatório o método da compra de materiais?

11 Fazer uma lista das matérias primas mais importantes, origem e vulnerabilidade do fornecimento.

12 Que posição ocupa nossa unidade produtiva no que se refere a uma ampla eficiência técnica, com respeito a nossos melhores concorrentes? com os melhores do mundo?

13 Existe uma alteração tecnológica importante que afetará os nossos produtos ou as nossas unidades produtivas?

14 Podemos contar com o necessário desenvolvimento por meio dos nossos setores de pesquisa e desenvolvimento ou deveríamos tratar de adquirir know how?

15 Qual é a nossa estrutura de transportes e seus custos?

16 Existe uma alteração tecnológica importante que afetará nossos produtos?

17 Que deveremos fazer para minimizar as hesitações temporárias e cíclicas dos produtos?

18 Comparação de qualidade e modernização da fábrica com outras fábricas, inclusive competidores estrangeiros. 
19 Tendências de equipamento na indústria, por exemplo: uso de computadores para programação, contrôles automáticos, miniaturização, equipamento programado, etc.

20 Porcentagem atual da capacidade básica da fábrica usada efetivamente.

21 Importância e localização da fábrica em relação aos principais fornecedores.

22 Canais de distribuição - avaliação da capacidade de localização atual em relação a êsses canais.

23 Economia da localização da fábrica em têrmos de custo de mão-de-obra e área de trabalhos especiais, a curto e longo prazo.

24 Qual tem sido a mão-de-obra especializada necessária para fabricar êste produto nos últimos cinco anos? Qual será daqui a dez anos?

25 Avaliação do programa de treinamento da mãc-de-obra e supervisão em vista das tendências do trabalho. Êsses programas estão desenvolvendo especialistas que serão necessários nos próximos anos?

26 Qual o tempo necessário aos departamentos de engenharia para adaptar a pesquisa para a produçãc? Qual é o acúmulo de serviço técnico?

27 Quais as modificações ocorridas nos últimos cinco anos? Quais foram antecipadas?

28 Está aumentando a produtividade da mão-de-obra? Caso contrário, quem é o responsável?

29 Como se comparam os índices de turnover do pessoal, absentismo, perda de tempo por acidentes, horas perdidas por conflitos, com a média da indústria em geral? Com nossos concorrentes maiores?

30 Estamos satisfeitos com os princípios básicos que sustentam nosso sistema de remuneração e estabelecem as diferentes categorias e condições de emprêgo?

\section{QUINTA SESSÃO: INOVAÇÃO TECNOLÓGICA}

1 Há evidência de que os executivos aspiram a melhorar o negócio atual em todos os sentidos? Que exemplos temos?

2 Está nosso Programa de Pesquisa e Desenvolvimento orientado comercialmente e de acôrdo com os objetivos de nosso negócio?

3 Discriminar os êxitos dos projetos mais importantes de pesquisa e desenvolvimento nos últimos cinco anos comparados com o plano original de expectativas.

4 Analisar os projetos atuais (novos prcdutos, processos novos e melhorados, estudos básicos, atenção a clientes, etc.), com relação a: 
- período de tempo para completar.

- recursos financeiros e humanos.

- quadro de lucros previstos.

- progresso efetuado para alcançar êsses lucros.

- principais patentes e sua dependência a estas.

- renda proveniente de royalties.

5 Estamos avaliando, sistemàticamente, os avanços tecnológicos para ver que melhoras se podem efetuar em nossos processos e produtos? para detectar ameaças e oportunidades a longo prazo?

6 Possuímos conhecimentos adequados do computador como ferramenta de contrôle?

7 Não seria melhor subcontratar outros para tratarem de Pesquisa e Desenvolvimentc do que realizá-lo nós mesmos?

8 Que planos teremos para cobrir as falhas que aparecerão em nossas receitas quando expirarem nossas patentes mais importantes?

9 Possui nossa Companhia o equipamento, competência e técnicos para fabricar um produto dêsse tipo, eficientemente?

10 Possui nossa Companhia organização de vendas e distribuição para vender êsse tipo de produto com êxito?

11 Esse produto acentua ou diminui a reputação que a emprêsa tem num ramo em particular?

12 Estamos interessados em despender tempo e dinheiro necessário para comercializar êsse tipo de produto?

\section{SEXTA SESSÃO: ESTRUTURA E DESENVOLVIMENTO DE EXECUTIVOS}

1 Estão detalhados claramente os objetivos da companhia e os resultados que espera obter?

2 Estão delegadas as responsabilidades de tal modo que se define claramente quem é o responsável pelos resultados obtidos?

3 Cada gerente tem estabelecido claramente que resultados deve obter com os padrões adequados de atuação e limites de prazc?

4 E clara a linha hierárquica?

5 Estão as técnicas de contrôle estreitamente ligadas com os resultados esperados de tal modo que resulta factivel a administração por exceção?

6 Qual é o grau de conhecimentos/experiência no grupo de novos executivos? Estamos aproveitando bem? Há cargos importantes vagos, especialmente com oportunidades futuras, que deveríamos preencher?

7 Há uma avaliação periódica da atuação de cada gerente e uma estimativa de seu futuro potencial? 
8 Confeccionam-se os planos de ação, sistemàticamente, segundo necessidades comprovadas, ou se desenvolvem iscladamente pela seção de treinamento?

9 Temos um plano de sucessão realista? Subsistem algumas vagas que ncs preocupam e que devemos preencher?

10 Nossa estrutura de salários e de promoções atrai e recompensa realmente os colaboradores destacados?

11 Predomina amplamente o sentido da responsabilidade quanto à obtenção de resultados? Ou é problemático preencher os postos difíceis e lutar contra a complacência?

5. COMPORTAMENTO ESTRATÉGICO versus RESULTADOS A CURTO PRAZO

No centro dos trabalhos para a formulação de uma estratégia há um conflito que freqüentemente assume proporções maiores: o conflito entre os objetivos a longo prazo e os a curto prazo. Todos sabemos que o planejamento a longo prazo apresenta diversas vantagens educativas para a gerência: permite compreensão mais clara dos futuros impactos sôbre as decisões atuais, maior consciência das mudanças econômicas e sociais, antecipação das áreas que requerem mudanças futuras, aumento de velocidade das informações relevantes para contrôle, implementação mais rápida das futuras decisões. Por outro lado, é sabido que os gerentes tendem a desprezar os objetivos estratégicos em benefício de resultados espetaculares a curto prazo porque percebem que a recompensa e as promoções, isto é, o sistema de compensação premia o desempenho espetacular imediato, em detrimento de uma contribuição para os resultados futuros do negócio. O próprio sistema de avaliação do desempenho dos gerentes tem em vista apenas a contribuição para os resultados anuais, isto é, a curto prazo. De certa forma, o sistema de avaliação e o da remuneração constituem a arena onde entram em conflito as filosofias do curto e longo prazo. Esta parece ser a maior barreira a um comportamento do tipo estratégico e será analisada, em maior detalhe, mais adiante. Antes, porém, serão levantadas tôdas as outras razões pelas quais os objetivos a longo prazo ficam prejudicados. 
Segundo BRUCE PAYNe ${ }^{5}$, existem pelo menos seis razões pelas quais o planejamento a longo prazo não vem sendo praticado mais intensamente: a) o alto executivo que deve colocar em prática o plano, freqüentemente, não aprovou o planejamento a longo prazo, em primeiro lugar, e dá-lhe simplesmente um apoio verbal; b) os objetivos da emprêsa são definidos muito superficialmente e não refletem todos os interêsses da companhia. Pior ainda, os objetivos e finalidades estabelecidos pelo plano não estão de acôrdo com as aspirações reais dos responsáveis pela firma; c) não houve experiência adequada para a realização do plano. Ou houve falha para completar os estudos envolvidos ao se prepararem os dados, ou a pesquisa não foi original e foi concebida fora de época; d) há uma tendência em se subestimarem a expansão e os lucros abaixo das capacidades da companhia para produzir; e) quando as respostas imediatas não são acessíveis, as pessoas ficam impacientes para com todo o projeto; f) as companhias falham em tomar providências para revisar, atualizar, periòdicamente, o plano em vista de mudanças na companhia, flutuações econômicas e mudanças nas tendências sociais.

Além das dificuldades resumidas acima, segundo E. KIRBY WARREN outras dificuldades vêm constituir barreira à estratégia dos negócios: ${ }^{6}$

- Pressão para lucros imediatos. As companhias submetidas a uma competição difícil e tendo recursos limitados não conseguem fazer planos a longo prazo. $O$ esfôrço precisa ser dirigido para o presente, e, se necessário, às expensas do futuro. As pequenas e vulneráveis emprêsas, em perigo de bancarrota, não se podem permitir diluir os recursos e se enganar com planos a longo prazo.

- A personalidade do presidente. Alguns dirigentes trabalham na base da agenda diária e respondem às pressões que recebem. São pessoas conscientes de pla-

5 PAyne, Bruce. Planning fot Company Growth, McGraw-Hill, 1963.

6 Warren, E. Kirby. Long Range Planning, The Executive Viewpoint, Prentice Hall, 1966. 
nos a curto prazo e da ação relâmpago. Tendem a desconfiar de tudo o que diz respeito ao futuro próximo.

- Alguns projetos não podem ser antecipados. Os projetos devem ter o seu curso previsto; realizar projetos não é antecipar os acontecimentos. Queira-se ou não, como dizia Michael KaMI, da Xerox, "tornar nove mulheres grávidas não irá produzir uma criança por mês".

- A personalidade dos assessôres de planejamento. Um Diretor de Planejamento deve: preparar estimativas de eventos que poderão ter impacto nos elementos do negócio; analisar os resultados para identificar dificuldades e oportunidades potenciais; coligir dados que sirvam de base para as suposições básicas; formular e analisar planos de ação alternativos; traduzir tais planos em têrmos financeiros; e preparar os dados de apoio. Ora, a escolha do Diretor de Planejamento, às vêzes, não é feliz. Mais freqüentemente se escolhe um ex-controller, ou um ex-gerente de desenvolvimento de produtos, ou um teórico hermético. Cada um dêsses ex-especialistas poderá sucumbir a suas deformações profissionais e prejudicar o próprio moral do programa. Um controller, por exemplo, pode ser tentado a projetar as tendências passadas no futuro, fazendo do futuro um espêlho do passado. Muito cuidado deve ser dedicado à escolha do homem que coordenará o plano estratégico.

- Os gerentes tendem a desprezar a estratégia em benefício de resultados a curto prazo. O ceticismo sôbre os planos a longo prazo resulta de que os gerentes sabem que a recompensa e as promoções provêm dos resultados produzidos por planos a curto prazo e não pela contribuição aos resultados a longo prazo. Considera E. KIRBY WARREN que o enfoque da Administração por Resultados de DRUCKeR não serve para avaliar o plano a longo prazo e até lhe cria obstáculos. Diz o autor: "A Administração por Resultados produ- 
ziu irresponsabilidade nos Gerentes de Divisão que passaram ao comportamento imediadista. $O$ têrmo staff foi abolido e êsses departamentos-staff foram transformados em serviços que assistem às divisões apenas se sua assistência é solicitada. Cada gerente foi solicitado a considerar-se presidente de um pequeno negócio dentro da companhia. Dada essa orientação, não é de se surpreender que se pense: "Só os resultados é que contam. Planejamento a longo prazo é um assunto da direção e não é comigo".

A crítica dêsse autor a DRUCKER não é justa porque não o compreendeu bem. DRUCKER tem proposto a Administração por Resultados como terapêutica para aquêles tipos de gerência que estão demasiado burocratizados, ou demasiado preocupados consigo mesmos, em detrimento dos negócios. Na grande emprêsa é comum encontrar gerentes alheios à realidade dos negócios; a soma dos esforços dêsses gerentes não está concentrada nos alvos vitais da emprêsa, mas em alvos fragmentários e, muitas vêzes, contraditórios, que cada um persegue, à luz de sua própria aspiração. A Administração por Resultados é um método de saneamento dêsse comportamento administrativo doentio, à medida que integra esforços e os concentra no essencial. A mentalidade a curto prazo é, sim, produzida quando se premia sòmente o resultado a curto prazo, ou o resultado a curto prazo em detrimento do longo prazo. De modo que, a rigor, WARREN está criticando não a DRUCKER, mas ao critério de compensação adotado em muitas emprêsas.

Prosseguindo, WARREN propõe uma conciliação do conflito entre curto e longo prazo. Eis algumas medidas: 1. "Os resultados esperados de cada gerente devem ser estabelecidos de forma a encorajá-lo a combinar objetivos a curto e a longo prazo". 2. "O enfoque deve reduzir ou superar a tendência dos gerentes de dar pouco tempo e talento aos planos a longo prazo, porque os resultados a curto prazo tendem a ser determinantes mais poderosos do sucesso gerencial". 3. "A alta administração deve estar 
provida de meios para medir a qualidade e a solidez do plano a longo prazo, dos planejadores e do processo de planejar". 4. "Êsses meios devem permitir determinar se os resultados indesejáveis a longo prazo são produto de uma administração ou se apesar da boa administração os resultados foram pobres por culpa dos planejadores". 5. "A avaliação deve ser feita por grupos de assessôres preparados para avaliar a solidez dos planos, planejadores e planejamento, sem comprometer sua relação com as divisões e subgrupos dentro da companhia".

Em suma, os sistemas de avaliação de desempenho, de remuneração e de promoção gerencial deveriam ter em conta tanto a contribuição a curto prazo (resultados anuais) como a contribuição a longo prazo (objetivos estratégicos). Em algumas companhias, costumam-se incluir nos formulários de avaliação de gerentes quesitos relacionados com os objetivos gerais a longo prazo da emprêsa e do departamento. Em outras, a remuneração dos gerentes é $50 \%$ fixa e $50 \%$ variável: a parte fixa relaciona-se com resultados permanentes (tarefas do cargo e objetivos a longo prazo) e a parte variável relaciona-se com os resultados variáveis expressos pelos objetivos anuais e planos de ação. A promoção, que é uma consequiência das avaliações, nessas companhias tem em vista tanto a contribuição a curto como a longo prazo. Êste tema é mencionado aqui apenas de passagem, pois merece uma reflexão mais profunda.

Crê-se que os pontos levantados acima serão úteis para o leitor de modo a imunizá-lo contra o ceticismo. A formação de uma consciência estratégica nos gerentes não será fácil, enquanto o comportamento dos dirigentes fôr ambíguo ou premiar apenas o resultado imediato.

6. CONCLUSÃO

O leitor encontra neste artigo uma situação com que algumas emprêsas brasileiras estão se defrontando: a passagem da administração a curto prazo (orçamento e objetivos anuais) para a administração a longo prazo 
(subordinação dos objetivos anuais a objetivos plurianuais). Esta transição requer um esfôrço não só da emprêsa, representado por desenvolvimento de técnicas de investigação e planejamento, como também de cada executivo que não será mais premiado apenas pelo desempenho espetacular imediato, mas pela contribuição aos resultados a longo prazo. A introdução do dado estratégico requer o esclarecimento de malentendidos comuns: a presença de objetivos a longo prazo não significa uma rigidez burocratizante. Além disso, não se pretende, infantilmente, predizer ou assegurar o futuro. Um dos objetivos de uma estratégia é garantir que as ações de hoje tenham maior consistência porque tomadas à luz de um futuro próximo.

Conscientemente ou não, tôda emprêsa tem sua estratégia, se assim entendemos a coerência que caracteriza o seu comportamento, o seu modo peculiar de agir. $O$ autor dêste trabalho postula a conscientização dessa estratégia, isto é, a tomada dessas ações inconscientes pela razão empresarial. Neste artigo foram identificados alguns tipos de estratégia. Foi visto que cada tipo é o resultado final de um conjunto de objetivos econômicos e não econômicos e das influências limitadoras do ambiente. A organização dêsses objetivos e limitações é chamada de hierarquia de objetivos.

Outro objetivo da estratégia é permitir maior flexibilidade de resposta às contingências imprevisíveis. A emprêsa, comumente, se prepara para fazer algo que ela prevê, seguramente, e que está dentro da margem do provável. Além disso, ela deve estar organizada para responder ou antecipar-se ao imprevisível. O impacto de um imprevisto atinge em cheio os resultados da emprêsa quando ela joga demasiado com um só produto, um só mercado ou um só tipo de consumidor, assim como quando ela depende demasiado do capital imobilizado em ativo fixo, estoques, maquinismos. A estratégia pretende atingir uma certa diversificação e flexibilidade. 
O presente artigo, para não deixar de oferecer ao leitor um pouco de prática, apresenta um método para formular a estratégia, mediante sessões preparatórias. $O$ leitor encontra aí aquelas perguntas relevantes que se costumam fazer nesse tipo de reunião. Várias perguntas foram cortadas dessas listas por parecerem mais detalhistas e operacionais do que o necessário nesse tipo de reunião.

Finalmente, há indicações de que a atitude dos executivos deve ser motivada a encarar a estratégia como um dado nôvo e relevante. $O$ comportamento estratégico requer algo mais do que o resultado a curto prazo.

\section{BIBLIOGRAFIA}

ANSOFF, H. IGor. Corporate Strategy, Nova Iorque, McGraw-Hill, 1965.

PAYNE, Bruce. Planning for Company Growth, McGraw-Hill, 1963.

WARREN, E. Kirby. Long-Range Planning: The Executive Viewpoint, Englewood Cliffs, J.J., Prentice Hall, Inc., 1966.

Thompson, Stewart. Como as Emprêsas Planejam, tradução brasileira, Management Center do Brasil, São Paulo, 1967. 